\title{
Improvement of the Vertical Dispersion of Pollutants Resulting From Chimneys by Thermosiphon Effect
}

\author{
${ }^{1}$ A. O. M. Mahmoud, ${ }^{2}$ J. Zinoubi, ${ }^{3}$ R. Ben Maad and ${ }^{3}$ A. Belghith \\ ${ }^{1}$ Faculty of Sciences and Techniques of Nouakchott, Department of Physics, BP 5026, Nouakchott, \\ Mauritania $^{2}$ \\ Preparatory Institute of the Engineers Studies of Nabeul, Academic Campus, El Merazka, 8000 Nabeul, \\ Tunisia \\ ${ }^{3}$ Faculty of Sciences of Tunis, Department of Physics, Laboratory of Energizing and Thermal and Mass \\ Transfers, El Manar 2092, Tunis, Tunisia
}

\begin{abstract}
The dispersion of pollutants, resulting from industrial chimneys, in the surrounding atmosphere made the interest in realizing emitting conditions appears. It also encourages the vertical dispersion of these pollutants. At a given wind velocity, the height of this dispersion is essentially a function of the thermal power and the flow rate at the chimney exit. To improve these qualities, we propose a system that could be integrated to the industrial chimney exit. An open-ended vertical cylinder of larger diameter essentially constitutes this system. In order to determine the characteristics of the resulting flow, we simulated the problem in the laboratory while studying the evolution of a free thermal plume generated by a disk heated uniformly by the Joule effect at a constant temperature. The thermal plume expands in a quiet environment of isotherm temperature. To study the thermosiphon effect, we surrounded the plume source by a vertical cylinder opened at the extremities. Thermal radiation emitted by the hot disk heats the cylinder wall. The pressure drop due to the acceleration of the flow at the cylinder inlet causes the appearance of thermosiphon effect around the thermal plume. The analysis of the average fields of velocity and temperature shows that the thermosiphon effect entails a good homogenization of the flow at the system exit. Furthermore, the comparison of the results obtained at the exit of the two studied systems shows a relative increase of the flow rate and the thermal power absorbed by the air of the order of 50\% under the thermosiphon effect. This result is expressed by a gain in the plume rise of the order of $40 \%$.
\end{abstract}

Keywords: industrial chimney; plume rise; thermosiphon effect; thermal plume; plume-thermosiphon interaction.

\section{INTRODUCTION}

The actual industrial development foresees the realization of the industrial installations of smoke emission and of combustion products, which illustrate ecological hazards or dangers for people and the natural balance. The exploitation of these installations poses relative problems to the atmospheric dispersion of the pollutants descended from chimneys. These pollutants disperse especially as they are given out to big height and that their temperature and their vertical velocity are raised $^{[1]}$. If the height of the dispersion is not sufficient, the folding of the pollutants to the soil creates the zones of "proximity pollution" in the urban surrounding, situated in the neighborhood of the emitting sources of pollutants. This pollution affects the health of population by its short-term direct action, but exercises also a longer-term toxicity for some pathology. In addition to the problems of health, the proximity pollution can procure an important olfactory discomfort and participates in the deterioration of the natural equilibrium. Otherwise, the analysis of plumes descended from an isolated chimney, above a flat and free land shows three phases in the vertical evolution of the plume ${ }^{[1]}$. A first phase where the plume is vertical and the vertical component of its proper velocity is superior to the horizontal wind velocity. In the second phase, the plume bends and becomes approximately horizontal. This phase ends when the vertical component of the plume velocity is in order of size of wind velocity fluctuations. A density of the plume gases equals the one of the atmospheric air characterizes the third phase: their diffusion depends only on the properties of the surrounding atmosphere (Fig.1.a). One sees therefore that in the first phase of the plume, the features of the flow at the chimney exit operate a determining role. On the other hand, in the third phase only the proper features of the surrounding atmosphere will intervene. For all these reasons, one often tries to improve the height reached by the plume

Corresponding Author: Jamil Zinoubi, Preparatory Institute of the Engineers Studies of Nabeul, Academic Campus, El Merazka, 8000 Nabeul, Tunisia, Tel.+216 98213 316; Fax. + 21671560723 
at the end of the second phase, called "plume rise" ${ }^{,[2]}$. In fact, the studies achieved in these last decades, relative to several types of industrial chimneys, indicated the physical parameters that permit to determine the plume rise from the features of the flow at the chimney exit. These studies agree well to show that at given wind velocity, the plume rise is essentially a function of the emitting conditions: velocity and temperature of the flow, synthesized by the thermal power emitted at the chimney exit. Thus, Priestley ${ }^{[3,4]}$ proposed theoretical approach that's so far considered as the most complete and the most interesting. It is the basis of most works that have been achieved to lead to practical formula of the plume rise evaluation. While integrating the equations governing the flow of the two first phases of the plume, Priestly found a formula binding the plume rise to the thermal power emitted, of the type: $h=5700 \gamma\left(\frac{\Phi^{\frac{1}{4}}}{V}\right)$. Other investigators ${ }^{[5-9]}$ tempted to make a statistical treatment of all available experimental data in order to get a formula that gives also account of the best set of these results. Among the got empiric formulas, the most fluently used for the evaluation of the plume rise ${ }^{[1]}$ are:

-Concawe's Formula ${ }^{[9]}$, established by a multiple regression method applied to the relative data in the site of Duisburg, is the shape: $h=86\left(\frac{\Phi^{\frac{1}{2}}}{V^{\frac{3}{4}}}\right)$.

-Moses and Carson's Formula ${ }^{[1,7]}$, established also from observations done in the majority in Duisburgis works, is the type: $h=82\left(\frac{\Phi^{\frac{1}{2}}}{V}\right)$

-Lucas, Moore and Spurr ${ }^{[5,6]}$ propose a formula of the type: $h=\alpha\left(\frac{\Phi^{\frac{1}{4}}}{V}\right)$, based on the theoretical study of Priestley and on observations done on the sites of four English thermal power stations.

The comparison of the plume rises calculated from these empiric formulas with those observed on the site $^{[1,8]}$ shows that the Concawe and Moses-Carson's formulas are the best in the domain of the weak plume rises; whereas the Lucas's formula presents a tendency to overestimate the weak plume rises.

It is therefore clear that to realize emitting conditions encouraging the vertical dispersion of the pollutants descended of a chimney, it is necessary to act either:

- On the increase of the chimney height: besides the technical problems that it poses, it is necessary to choose the site of the chimney in order to minimize the aerodynamic and thermal interactions on the one hand due to the metallic structure of the pylon well, and to the buildings of proximity on the other hand.

- On the improvement of the plume rise while increasing the thermal power emitted at the chimney exit; what requires a supplementary consumption of

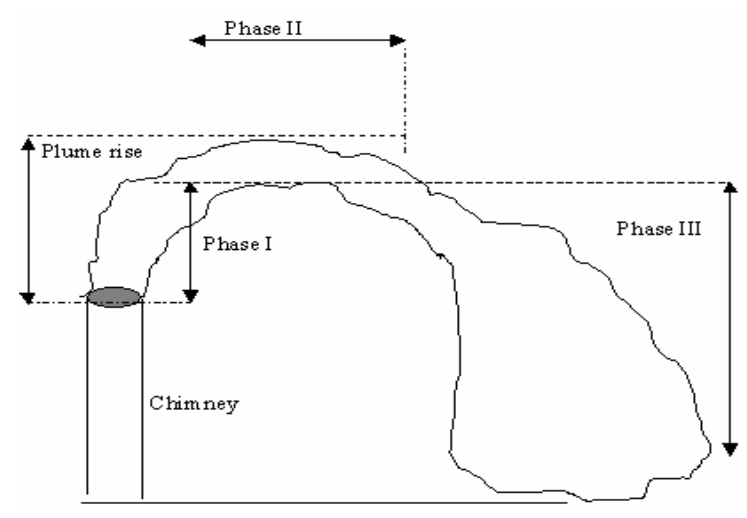

Fig.1.a: Plume resulting from chimney

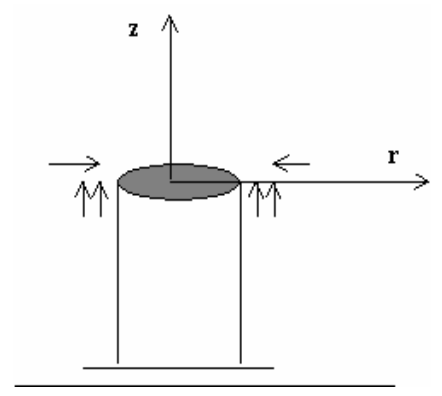

Fig.1.b: Thermal plume simulating the chimney

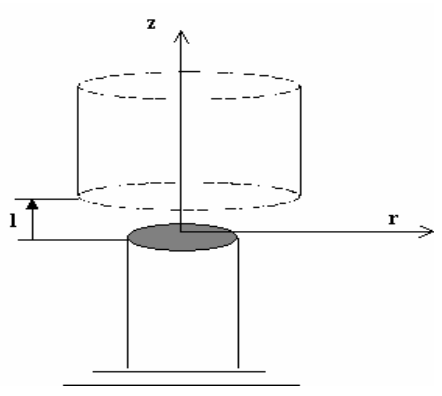

Fig.1.c: Thermosiphon system proposed

energy capable to reach $20 \%$ of the power produced by the chimneys of thermal power stations ${ }^{[1]}$.

It is in the object to improve the industrial chimney efficiency and to increase the plume rise that we propose to place at the chimney exit an open-ended insulated vertical cylinder with a bigger diameter. In order to determine the different parameters intervening in the system, we simulated this type of flow in the laboratory, while studying, in a first stage, the evolution of a free thermal plume generated by a circular disk uniformly heated at $300{ }^{\circ} \mathrm{C}$. The disk is placed on a frame above the ground to allow air feeding from below (Fig.1.b). In a second stage, this disk is introduced at the entrance of a vertical cylinder open at both ends (Fig.1.c). 


\section{MATERIALS AND METHODS}

The experimental apparatus is shown in Fig.2. The numbers in the description presented below refer to the part numbers of Fig.2.

The thermal plume is created by a flat $\operatorname{disk}^{(1)}$ with a diameter of $0.07 \mathrm{~m}$ electrically heated by the Joule effect to a surface temperature of $300^{\circ} \mathrm{C}$. In order to study the thermosiphon effect, the disk is placed at the entrance of the open ended steel vertical cylinder ${ }^{(2)}$, which has a diameter of $0.15 \mathrm{~m}$ and a height of $0.5 \mathrm{~m}$. The system was placed on a $0.8 \mathrm{~m}$ frame length above the ground to allow air supply from below ${ }^{(3)}$. The uniformity of the source surface temperature was obtained by the use of wire resistors mounted behind the disk. A thermal regulation apparatus kept the temperature of the disk as uniform as possible within a good approximation. Al-Cr thermocouples were used to measure the surface temperature of the disk. The temperature difference between the end and the centre of the disk is less than $5{ }^{\circ} \mathrm{C}$. The vertical cylinder was thermally insulated by a $0.02 \mathrm{~m}$ thickness Armaflex cylindrical bed shape ${ }^{(4)}$.

The strong dependence of the flow on the surrounding conditions requires conducting the experiment in a quiet atmosphere. To get this effect, the experimental device has been placed in an independent closed room.

To explore the thermal and the dynamic average fields inside the cylinder a resistant wire anemometer at constant current ${ }^{(5)}$ was used. This technique adopted for a long time by Doan Kim-Son et al. ${ }^{[10]}$, in a natural convection study, is based on the principle of the resistance variation of a platinum wire $(7.5 \mu \mathrm{m}$ in diameter ). The velocity and the temperature of the fluid are the two parameters susceptible to make the electrical resistance of the wire vary. All physical phenomena susceptible to make this resistance vary are therefore measurable. Doan Kim-Son et al. ${ }^{[10]}$ showed that a supply of $1.2 \mathrm{~mA}$ current makes the probe solely sensitive to the temperature (cold wire), and a supply of $38 \mathrm{~mA}$ current, makes it sensitive to the temperature and the velocity (hot wire). The probe calibration allows the determination of the velocity and the temperature of the flow from the voltage across the probe $^{[10]}$.

In order to avoid the disruption of the flow, the probe was introduced vertically, through the system exit, so that its sensitive wire was perpendicular to the ascending flow. The wire thermal inertia (the wire time constant is approximately equal to $1 \mathrm{~ms}$ ) did not introduce any measurement errors, especially at the low frequencies found in plumes ${ }^{[11]}$. Errors due to the probe calibration are lower than $1 \%$.

A computer driven displacement system ${ }^{(6)}$, allowing the traversing of the probe in two directions, was used to explore the thermal and dynamic average fields at every level of the flow. The minimal displacement in the vertical direction is $10^{-3} \mathrm{~m}$, whereas in the horizontal direction it is $2.10^{-5} \mathrm{~m}$.

A computer ${ }^{(7)}$ equipped with a data acquisition card acquires instantaneous signal values at $10 \mathrm{~ms}$ intervals and records the digitized signals for further statistical processing ${ }^{(8)}$.

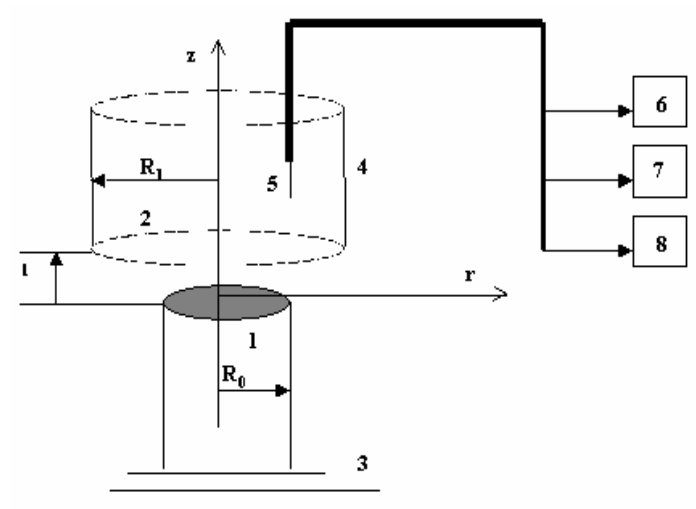

Fig.2: Experimental apparatus

\section{RESULTS AND DISCUSSION}

The experimental study is carried out in the particular case of: $\mathrm{Gr}=1.5610^{7}, \mathrm{~A}=0.15$ and $\mathrm{R}^{*}=$ 0.46. In order to determine the reference parameters, the physical properties of the fluid are evaluated at a reference temperature $\left(\mathrm{T}_{\mathrm{r}}\right)$. Furthermore, the experimental verification of the axial symmetry of the flow permitted us to limit the radial evolution of the temperature and the velocity at the radius system.

Average flow structure of the thermal plume evolving in a calm and unlimited environment: Fig. 3 shows the vertical evolution of dimensionless average temperature and velocity of the flow on the plume axis. These profiles reveal two different evolutions of the temperature and velocity at different levels $Z_{1}$. In fact, in the first zone near the hot source $\left(Z_{1}<0.3\right)$, the thermal and dynamic gradients are relatively intense. At the level $Z_{1}=0.3$, the axial velocity maximum is reached when a balance of the buoyancy forces and viscous forces occurs. From this level $\left(Z_{1}>0.3\right)$, the axial velocity and temperature of the flow decrease slowly with a low longitudinal gradient. This evolution is comparable to free plume of a lateral aspiration ${ }^{[11]}$, generated by a disk, or by a hollow portion of sphere heated at $500{ }^{\circ} \mathrm{C}$

Fig.4.a presents the radial evolution of the dimensionless average temperature of the plume flow at different levels $Z_{1}$. For the levels near the hot source $\left(Z_{1}<0.3\right)$, this figure shows a low decrease of the temperature on the plume axis, due to a strong penetration of the fresh outside air. This Figure indicates clearly an important transverse gradient of 
temperature on side of the axis. As $Z_{1}$ increases, the average temperatures of the flow decrease, but, the transverse gradients keep their intensity until the level $Z_{1}=0.3$ where the profiles become more flatten. This brutal decrease of the transverse thermal gradients confirms the existence of a new flow pattern where the plume is transformed into a hot air.

Fig.4.b gives the radial distribution of the vertical component of the dimensionless average velocity at different levels $Z_{1}$. These profiles show an important transverse gradient with a low over-velocity on side of the plume axis. This strong gradient is the principal cause of the mechanism of the ambient air entrainment on the frontiers of the plume. On the other hand, from $Z_{1}=0.3$, the global level of the vertical velocity falls in the central part, and the profiles widen, thus indicating the apparition of a new structure where the turbulence is established

It is important to notify that the average flow structure obtained is comparable to free plume of the lateral aspiration $^{[11]}$, generated by a disk, or by hemispherical source at $500^{\circ} \mathrm{C}$

Study of the thermosiphon effect on the thermal plume flow: To study the thermosiphon effect on the free plume flow, we placed above the hot source a vertical cylinder. The cylindrical wall is heated by a thermal radiation emitted by the heating disk. The temperature difference with the outside environment entails the movement of the fluid at the system entry. The pressure drop due to the acceleration of the flow at the cylinder inlet generates the thermosiphon effect around the thermal plume. In order to determine the optimum position of the cylinder in relation to the source, we studied three positions: $1^{*}=-0.67,0.27$ and 0.80 on the flow at the system exit and on the thermal power absorbed by the air.

Determination of the optimum position of the cylinder: Fig.5.a shows the radial evolution of the dimensionless average temperature of the plumethermosiphon interaction flow at the system exit and for different positions of the cylinder $\mathrm{l}^{*}$. It is clear that the temperature of the flow is uniform at the position $1^{*}=-0.67$ where the plume source is driven inside the cylinder of $5 \mathrm{Cm}$. So, we also note that the global level of the flow temperature is the most important.

The radial evolution of the vertical component of the dimensionless average velocity at the system exit and for different positions of the cylinder $1^{*}$ is given in Fig.5.b. These profiles also show there at the position $1^{*}=-0.67$, the flow velocity is uniform.

Fig.6.a presents the vertical evolution of the thermal power ratio $\mathrm{H}_{\mathrm{r}}$ for different positions $\mathrm{l}^{*}$. These profiles show clearly a considerable improvement of the thermal power absorbed by the air at the position $1^{*}=-0.67$. Furthermore, an improvement of the flow rate ratio $Q_{r}$ at the same position $\left(1^{*}=-0.67\right)$ is noted in Fig.6.b.

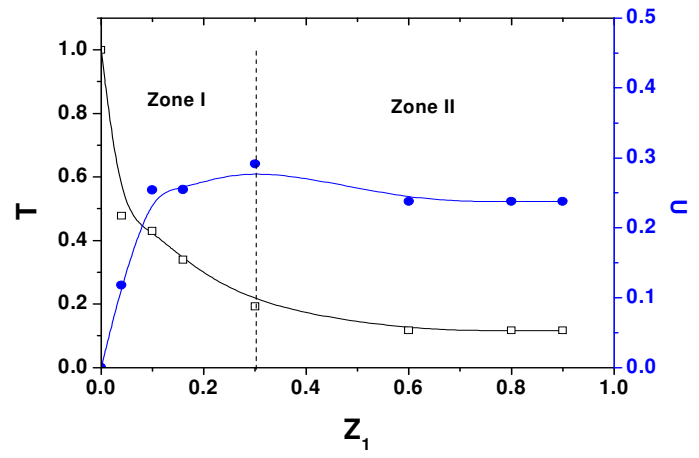

Fig.3: Axial evolution of dimensionless average temperature and velocity of the plume

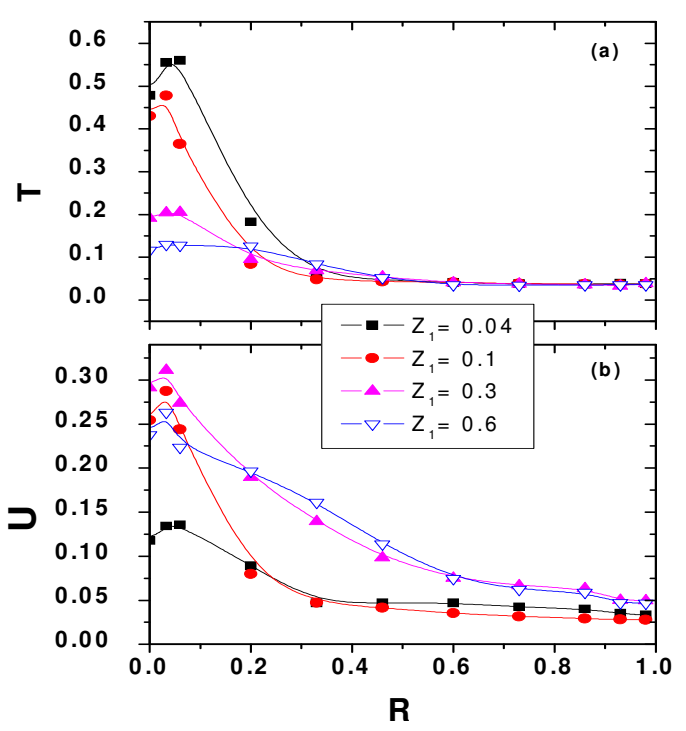

Fig.4: Radial evolution of the dimensionless average temperature and velocity of the plume (a): Temperature; (b): Velocity

These results indicate clearly that the optimum position of the cylinder is $1^{*}=-0.67^{[12]}$. It will be therefore interesting to study the resulting flow of plumethermosiphon interaction with this position.

Average flow structure of plume-thermosiphon interaction with the optimum position of the cylinder: The axial evolution of the dimensionless average temperature and velocity of the plumethermosiphon flow is given in Fig.7. This evolution shows three different variations of the flow along the plume axis. In fact, for $Z_{1} \leq 0.1$, the flow is strongly influenced by the presence of the hot source since the entrance of the cylinder. At the levels $0.1<\mathrm{Z}_{1}$ $\leq 0.3$, an important acceleration of the flow is observed. This is due to the relative great importance of the buoyancy forces that dominate the flow. At the level $\mathrm{Z}_{1}=0.3$, the axial velocity reaches its maximum and a balance of the buoyancy forces and viscous forces 
occurs. From this level, a deceleration process of the axial velocity of the flow starts.

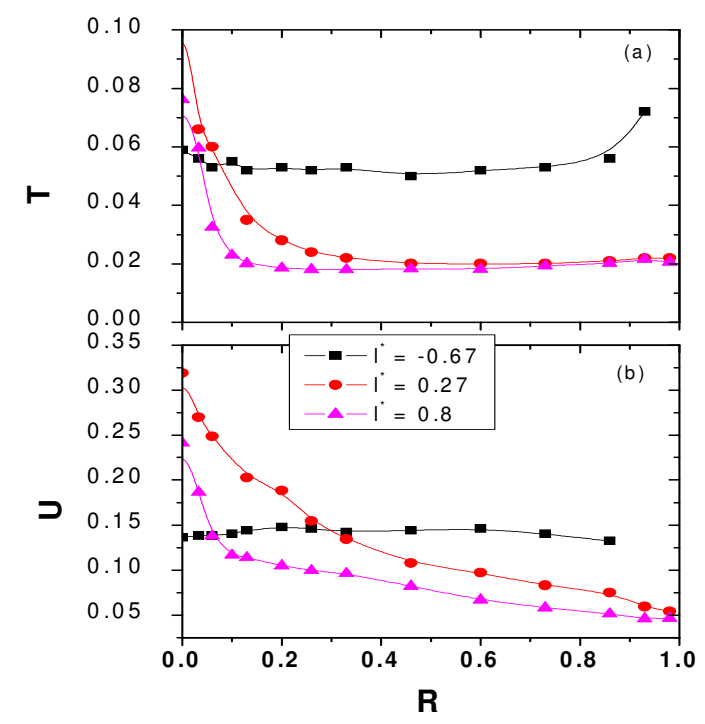

Fig.5: Radial evolution of the dimensionless average temperature and velocity of the plumethermosiphon flow at the system exit (a): Temperature; (b): Velocity

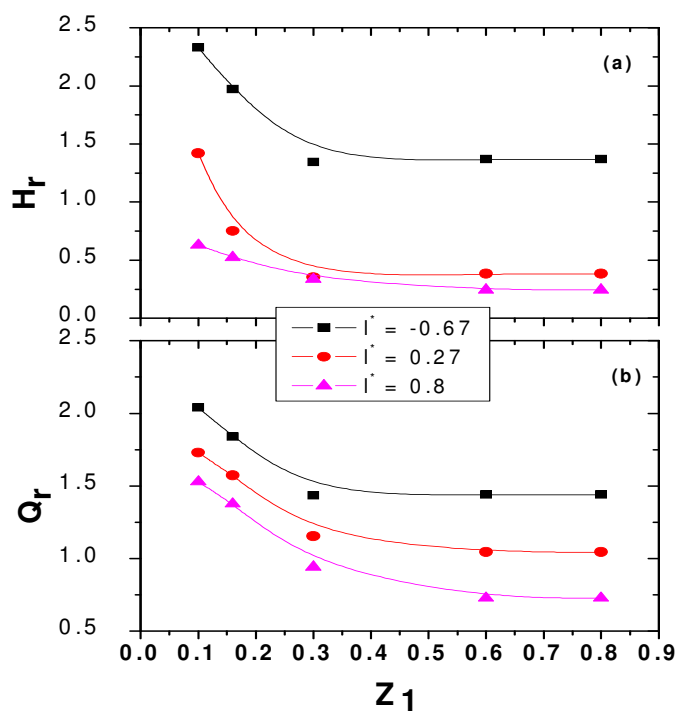

Fig.6: Vertical evolution of flow rate ratio $\mathrm{Q}_{\mathrm{r}}$ and the thermal power ratio $\mathrm{H}_{\mathrm{r}}$ for different positions of the cylinder

Fig.8.a presents the radial distribution of the dimensionless average temperature of the flow at different levels $Z_{1}$. In fact, in the zone close to the hot source $\left(Z_{1} \leq 0.1\right)$, the profile has two extrema with a maximum situated at $\mathrm{R}=0.2$, and a minimum on the plume axis. Flow visualization ${ }^{[12,13]}$ permitted to show that the appearance of this maximum is attributed to the development of rotating rolls on the hot disk area. At the intermediate levels $\left(0.1<Z_{1} \leq 0.3\right)$, this figure shows temperature profiles more and more flattened. In the last zone $\left(Z_{1}=0.6\right.$ and 0.8$)$, the temperature profiles become self-similar and almost identical to show therefore the establishment of the turbulence in the superior part of the cylinder.

The radial evolution of the dimensionless average vertical velocity of the flow at different levels $Z_{1}$ is given in Fig.8.b. As it has previously been shown, these profiles present three different aspects of the global flow structure. In fact, for the first levels near the hot source $\left(Z_{1} \leq 0.1\right)$ the velocity profiles evolve in a structure of two extrema with a minimum on the axis and a maximum situated on the side of the hot source $(\mathrm{R}=0.46)$. This maximum results from the interaction between the plume and the thermosiphon that surrounds it. At the intermediate levels, $\left(0.1<\mathrm{Z}_{1} \leq 0.3\right)$, this figure shows the apparition of a new flow structure where the velocity profiles present an only one maximum on the axis. In the superior part of the cylinder $\left(Z_{1}>0.3\right)$, the profiles are self-similar and commonly regrouped around one curve. So, the turbulence is fully developed. The flow velocity remains uniform with a low transverse gradient.

Comparative study of the thermal and dynamic average fields of the free plume flow and with thermosiphon: In Fig.9 are given the axial evolution of the temperature and the vertical velocity of the flow in the case of the free plume flow and with thermosiphon at the optimum position of the cylinder. This figure shows that the thermosiphon effect entails a strong decrease of the axial values of the temperature and the velocity of the plume flow. In the zone relatively distant of the source $\left(Z_{1}>0.3\right)$, the profiles show that the axial temperatures come closer in the two studied cases; whereas the difference between the velocities remains important and maintains at a constant value.

Fig.10.a gives the radial distribution of the dimensionless average temperature of the free plume flow and with thermosiphon at the closest level to the hot source $\left(Z_{1}=0.04\right)$. This Figure shows a radial widening of the average field of the flow temperature under the thermosiphon effect. Thus, the maximum of the temperature moves away on the side of the plume axis and locates at a mid-radius of the source $(R=0.2)$. At the same level $\left(Z_{1}=0.04\right)$, Fig.11.a presents the radial distribution of the vertical component of the dimensionless average velocity of the flow in the two studied cases. This figure shows the important effect of the thermosiphon flow on the dynamic of the plume. Thus, the plume is strongly attracted, to the cylindrical wall, by the thermosiphon that surrounds it. The comparison of the temperature and velocity profiles at the exit of the two studied systems shows that the thermosiphon effect entails an activation of the mixture of the fluid and provides a good homogenization of the flow (Figs.10.b and 11.b). 




Fig.7: Axial evolution of the dimensionless average temperature and velocity of the plumethermosiphon flow at $1^{*}=-0.67$



Fig.8: Radial evolution of the dimensionless average temperature and velocity of the plume thermosiphon flow at $l^{*}=-0.67$ :
(a): Temperature; (b): Velocity

Comparative study of the average flow rates of the free plume flow and with thermosiphon: Fig.12.a presents the vertical evolution of the flow rate ratio $Q_{r}$ inside the cylinder. This figure shows clearly a considerable improvement of the flow rate under the thermosiphon effect. This improvement is due to an important thermal radiation emitted by the hot disk and absorbed by the cylinder wall, which induces a more important thermosiphon effect. Therefore, the comparison of the flow rates at the exit of the two studied systems shows a relative increase of the order of $50 \%$ under the thermosiphon effect.

Comparative study of the thermal powers absorbed by the air of the free plume flow and with thermosiphon: In Fig.12.b is given the vertical evolution of the thermal power ratio $\mathrm{H}_{\mathrm{r}}$. This figure shows clearly a remarkable improvement of the thermal power absorbed by the air resulting from the thermosiphon effect. In fact, the totality of the thermal radiation, emitted by the plume source, is captured by the internal cylindrical wall ${ }^{[12]}$.

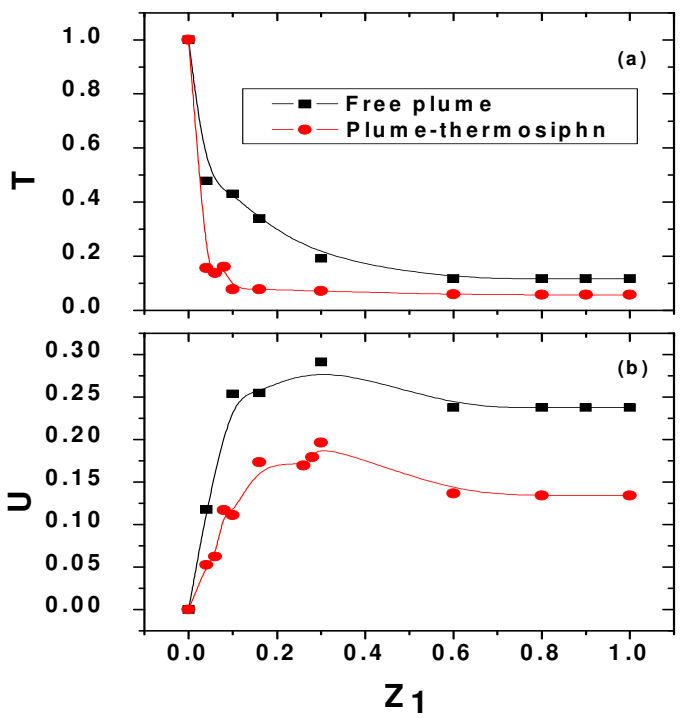

Fig.9: Axial evolution of the dimensionless average temperature and velocity of the free plume and with thermosiphon of the free plume and with thermosiphon

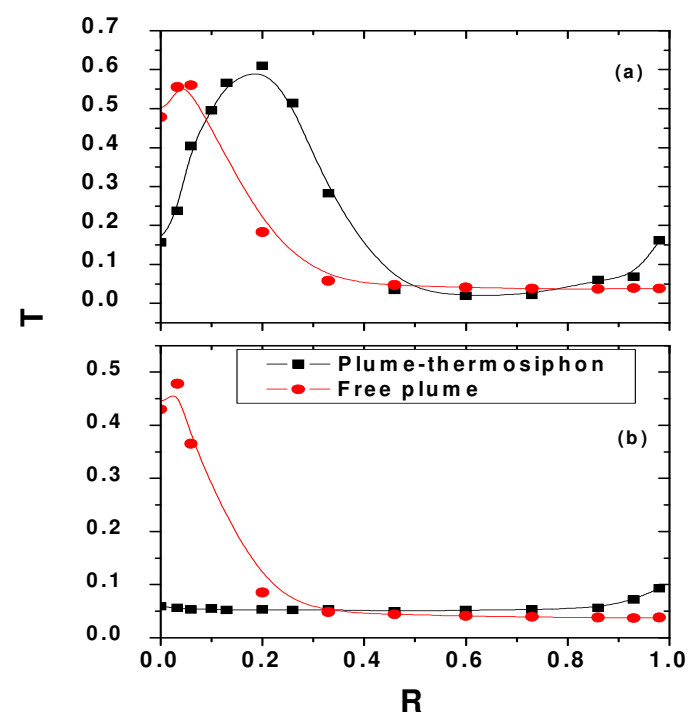

Fig.10: Radial evolution of the dimensionless average temperature of the free plume and with thermosiphon at $Z_{1}=0.04$ and at the exit of the two studied systems (a): at $Z_{1}=0.04$; (b): at the exit

The air aspirated from below by the thermosiphon effect recuperates this energy by natural convection with the wall during its ascension. On the other hand, 
the formation of the rotating rolls on the hot disk area encourages the heat transfer and accelerates the mixture of the fluid ${ }^{[12,13]}$.



Fig.11: Radial evolution of the dimensionless average velocity of the free plume and with thermosiphon at $\mathrm{Z}_{1}=0.04$ and at the exit of the two studied systems (a): at $\mathrm{Z}_{1}=0.04$; (b): at the exit

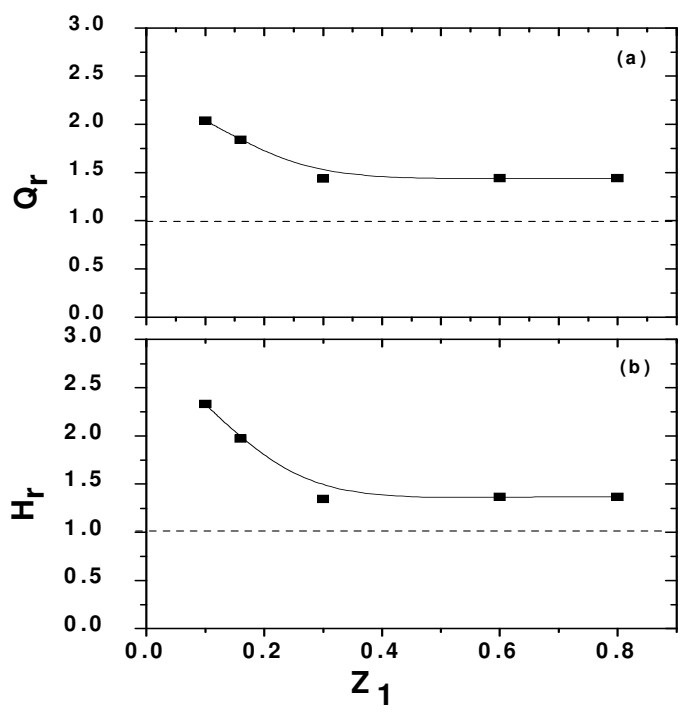

Fig.12: Vertical evolution of the flow rate ratio $\mathrm{Q}_{\mathrm{r}}$ and the thermal power ratio $H_{r}$ at $1^{*}=-0.67$

Furthermore, the comparison of the thermal powers absorbed by the air at the exit of the two studied systems shows a relative increase of the order of $50 \%$ under the thermosiphon effect.

According to the empiric formulas presented previously, the improvement of the thermal power absorbed by the air resulting of the thermosiphon effect is shown in an increase of the plume rise. The comparison of the plume rise in the two studied cases gives the following relation:

$\mathrm{h}^{*}=\frac{\mathrm{h}_{\mathrm{th}}}{\mathrm{h}_{\mathrm{p}}}=\left(\frac{\Phi_{\mathrm{th}}}{\Phi_{\mathrm{p}}}\right)^{\mathrm{a}}=\left(\frac{\mathrm{H}_{\mathrm{th}}}{\mathrm{H}_{\mathrm{p}}}\right)^{\mathrm{a}} \quad ; \mathrm{a}=1 / 2^{[7,9]}$ or $\mathrm{a}=1 / 4^{[3,4]}$

Thus, at the exit of the two studied systems, the ratio $h^{*}$ of the plume rises with the thermosiphon in relation to the one of the free plume for the different formulas, is given in the table (Tab.1). We note that the plume rise is improved by the thermosiphon effect, whatever is the empiric formula used.

Table 1: the ratio $\mathrm{h}^{*}$ of the plume rises for different formulas

\begin{tabular}{ccc}
\hline & $\begin{array}{c}\text { Mose-Carson } \\
\text { Concawe's }{ }^{[1,7]} \text { formula }\end{array}$ & $\begin{array}{c}\text { Priestley } \\
\text { Lucas's }{ }^{[6]} \text { formula }\end{array}$ \\
\hline $\mathrm{h}^{*}$ & 1.44 & 1.2 \\
\hline
\end{tabular}

\section{CONCLUSION}

This study has permitted to determine the thermosiphon effect on a thermal plume flow generated by a heating disk and evolving in a quiet environment of isotherm temperature. This effect especially entails:

- The apparition of a supplementary zone, just at the system entrance, that is added to the two classic zones.

- An increase of the flow rate.

- An intensification of the thermal power absorbed by the air.

- A good homogenization of the fluid at the system exit, permitting to encourage the mixture of the pollutants constituent descended from chimney.

- A noticeable improvement of the plume rise.

Thus, the thermosiphon effect intervenes to limit the lateral expansion of the plume, to activate the mixture of the fluid and to push it toward the upper. The integration of this system at the chimney exit permits to contribute efficiently to the improvement of the vertical scattering of pollutants descended from an industrial chimney in the atmosphere.

\section{NOMENCLATURE}

A : Shape ratio of cylinder, $\left(=\frac{\mathrm{R}_{1}}{\mathrm{~L}}\right)$

$\mathrm{g}$ : Gravitational acceleration, $\mathrm{m} . \mathrm{s}^{-2}$

Gr : Grashof number , $\left(=\frac{\mathrm{g} \beta\left(\mathrm{T}_{\mathrm{s}}-\mathrm{T}_{\mathrm{a}}\right) \mathrm{R}_{1}^{3}}{\mathrm{v}_{2}}\right)$

Gr* : Modified Grashof number, (= Gr.A)

$\mathrm{h}$ : Plume rise of the chimney, $\mathrm{m}$

$\mathrm{h}_{\mathrm{p}}$ : Plume rise of the thermal plume, $\mathrm{m}$

$\mathrm{h}_{\mathrm{th}}$ : Plume rise of the thermal plume with thermosiphon, $m$

H: Dimensionless thermal power absorbed by the air,

$$
\left(=\frac{2 \pi C_{p} \int_{0}^{R_{1}} \rho u r\left(T-T_{a}\right) d r}{\pi \rho_{0} C_{p} L v G_{r}^{* \frac{1}{2}}\left(T_{s}-T_{a}\right)}=2 \int_{0}^{1} \rho^{*} \text { URTdR }\right)
$$


$\mathrm{H}_{\mathrm{p}}$ : Dimensionless thermal power absorbed by the air of the thermal plume

$\mathrm{H}_{\mathrm{th}}$ : Dimensionless thermal power absorbed by the air of the plume-thermosiphon interaction flow

$\mathrm{H}_{\mathrm{r}}$ : Thermal power ratio, $\left(=\frac{\mathrm{H}_{\text {th }}}{\mathrm{H}_{\mathrm{p}}}\right)$

1: Spacing between the hot source and the cylinder, $\mathrm{cm}$

$1^{*}$ : Dimensionless spacing source-cylinder, $\left(=\frac{1}{\mathrm{R}_{1}}\right)$

L: Cylinder height, $\mathrm{m}$

$\mathrm{Q}_{\mathrm{v}}$ : Dimensionless average flow rate,

$$
\left(=\frac{2 \pi \int_{0}^{R_{1}} \mathrm{rudr}}{\pi \nu \mathrm{LG}_{\mathrm{r}}{ }^{* \frac{1}{2}}}=2 \int_{0}^{1} \mathrm{URdR}\right)
$$

$\mathrm{Q}_{\mathrm{p}}$ : Dimensionless average free plume flow rate

$\mathrm{Q}_{\mathrm{th}}$ : Dimensionless average plume-thermosiphon interaction flow rate

$\mathrm{Q}_{\mathrm{r}}$ : Flow rate ratio, $\left(=\frac{\mathrm{Q}_{\mathrm{th}}}{\mathrm{Q}_{\mathrm{p}}}\right)$

$\mathrm{r}$ : Radial coordinate, $\mathrm{m}$

$\mathrm{R}_{1}$ : Radius of cylinder, $\mathrm{m}$

$\mathrm{R}_{0}$ : Radius of disk, $\mathrm{m}$

$\mathrm{R}$ : Dimensionless radial coordinate, $\left(=\frac{\mathrm{r}}{\mathrm{R}_{1}}\right)$

$\mathrm{R}^{*}$ : Radius ratio, $\left(=\frac{\mathrm{R}_{0}}{\mathrm{R}_{1}}\right)$

$\mathrm{T}_{1}$ : Average temperature, ${ }^{\circ} \mathrm{C}$

$\mathrm{T}_{\mathrm{a}}$ : Ambient air temperature, ${ }^{\circ} \mathrm{C}$

$\mathrm{T}_{\mathrm{p}}$ : Mean temperature of the cylinder walls, ${ }^{\circ} \mathrm{C}$

$\mathrm{T}_{\mathrm{r}}$ : Reference temperature, $\left(=\frac{\mathrm{T}_{\mathrm{p}}+\mathrm{T}_{\mathrm{a}}}{2}\right)$

$\mathrm{T}_{\mathrm{s}}$ : Temperature of the hot disk, ${ }^{\circ} \mathrm{C}$

$\mathrm{T}$ : Dimensionless average temperature, $\left(=\frac{\mathrm{T}_{1}-\mathrm{T}_{\mathrm{a}}}{\mathrm{T}_{\mathrm{s}}-\mathrm{T}_{\mathrm{a}}}\right)$

$\mathrm{u}$ : Vertical average component velocity, $\mathrm{m} . \mathrm{s}^{-1}$

U: Dimensionless vertical component velocity, $\left(=\frac{\mathrm{uR}_{1}^{2}}{\mathrm{LvG}_{\mathrm{r}}^{* \frac{1}{2}}}\right)$

$\mathrm{z}$ : Vertical coordinate, $\mathrm{m}$

$\mathrm{Z}_{1}$ : Dimensionless coordinate, $\left(=\frac{\mathrm{Z}}{\mathrm{L}}\right)$

$\mathrm{V}$ : Wind velocity at the plume top level, $\mathrm{ms}^{-1}$

\section{Greek symbols}

$\alpha$ : Coefficient function of the site, atmospheric stability and the chimneys type

$\beta$ : Thermal expansion coefficient, $\mathrm{K}^{-1}$

$v$ : Kinematic fluid viscosity, $\mathrm{m}^{2} \cdot \mathrm{s}^{-1}$

$\rho$ : Air density at average temperature, $\mathrm{Kg} \cdot \mathrm{m}^{-3}$

$\rho_{0}$ : Air density at ambient temperature, $\mathrm{Kg} \cdot \mathrm{m}^{-3}$

$\rho^{*}$ : Density ratio $\left(=\frac{\rho}{\rho_{0}}\right)$

$\Phi$ : Thermal power absorbed by the air,

$$
\left(=2 \pi \mathrm{C}_{\mathrm{p}} \int_{0}^{\mathrm{R}_{1}} \rho \mathrm{pur}\left(\mathrm{T}-\mathrm{T}_{\mathrm{a}}\right) \mathrm{dr}\right), \text { Watt }
$$

$\Phi_{\mathrm{p}}$ : Thermal power absorbed by the plume air, Watt

$\Phi_{\text {th }}$ : Thermal power absorbed by the plumethermosiphon air, Watt $\gamma$ : Coefficient function of the atmospheric stability degree

\section{REFERENCES}

1. Michel H., 1985. Mécaniques des Fluides Appliquées aux Problèmes d'Aménagement et d'Energétique, Direction des études et Recherche d'électricité de France.

2. Holland, T. Z., 1953. A Meteorological Survey of the Oak Ridge Area. U. S. A. E. C. report ORO-99554.

3. Priestley, C. H. B., 1956. A working theory of the Bent-Over plume of hot gas: Quarterly J. R. Met. Soc., 82:165.

4. Priestley, C. H. B., 1953. Buoyant Motion in a Turbulent Environment. Australian J. of Physics, $6: 279$.

5. Spurr, G., 1957. The Bent-Over plume of gas, Quart. J. R. Met. Soc., 83.

6. Lucas, D. H., D. J. Moore, G. Spurr, 1963. The rise of hot plumes from chimneys. Air and Water Pollut. Int. J. 7: 473.

7. Moses, H., J. E. Carson, 1968, Stack Design Parameters influencing plume rise. J. Air Pollut. Control Ass., 18: 454.

8. Briggs, G., 1965. A plume Rise Model Compared with Observation. J. Air. Pollut. Control Ass., 15: 433.

9. Brummage, K. G., 1968. The calculation of atmospheric Dispersion from a Stack. Atm. Envir. 2: 197.

10. Doan, K. S., M. Stage., J. Coutanceau, 1975. Transfert de chaleur entre un fil anémométrique court et un écoulement permanent à faible vitesse, Rev. Gén. Therm, 160 : 951-956.

11. Agator, J. M., 1983. Contribution à l'étude de la structure turbulente d'un panache thermique à symétrie axiale-Interaction du panache avec son environnement limité. Thèse de Docteur-Ingénieur, Université de Poitiers.

12. Zinoubi, J., R. Ben Maad., A. Belghith, 2004. Influence of the vertical source - cylinder spacing on the interaction of a thermal plume with a thermosiphon flow : an experimental study, Exp. Thermal and Fluid Science, 28: 329-336.

13. Mahmoud, A. O. M., R. Ben Maad., A. Belghith, 1998. Interaction d'un écoulement de thermosiphon avec un panache thermique à symétrie axiale: Etude expérimentale, Rev. Gén. Therm., 37 : 385-396. 